\title{
Cross-cultural Leadership Effectiveness: Perspectives from Non-Western Leaders
}

\author{
Hsiu-ching $\mathrm{Ko}^{1}$ \\ ${ }^{1}$ Department of Mass Communication, Chang Jung Christian University, Tainan, Taiwan \\ *Correspondence: Department of Mass Communication, Chang Jung Christian University, No.1, Changda Rd., \\ Gueiren District, Tainan City 71101, Taiwan(R.O.C.). Tel: 886-921-309-439. E-mail: ching_khc@hotmail.com
}

Received: May 9, $2015 \quad$ Accepted: June 6, $2015 \quad$ Online Published: September 16, 2015

doi:10.5430/mos.v2n4p1 URL: http://dx.doi.org/10.5430/mos.v2n4p1

\begin{abstract}
Qualitative, in-depth interviews were used to explore determinants of cross-cultural leadership effectiveness from the perspectives of non-Western leaders. Data were collected from semi-structured interviews and self-reported performance from 12 expatriate Taiwanese managers. Analyses suggest three categorical determinants of cross-cultural leadership effectiveness: personality characteristics, leadership strategies, and core competencies. Findings provide insightful information, facts, and facets related to the practice of cross-cultural leadership from the perspectives of non-Western expatriate managers. Results provide empirical evidence that contributes to the theory of cross-cultural leadership, expatriate management, and global leadership development, and evidence for expatriate managers, trainers, and corporations.
\end{abstract}

Keywords: expatriate manager; cross-cultural leadership; cross-cultural competency; personality characteristics; leadership strategy

\section{Introduction}

Globalization encouraged most multinational corporations (MNCs) to change to compete in global markets, increasing mobility of human resources across the globe, giving rise to the challenge of cross-cultural interactions between employees and managers from disparate cultures (Adler, 1997; Martviuk, 2007), and making cross-cultural leadership imperative. However, as MNCs expanded businesses globally to maintain and enhance global competitiveness, two major concerns appeared: (a) a high failure rate of international assignments and (b) shortages of leaders with the ability to cope with cultural challenges of doing business overseas (Johnson et al., 2006). According to Livermore (2010), 90\% of leaders from 68 countries viewed cross-cultural leadership as a top management challenge for the next century. Similarly, PriceWaterhouseCoopers' $14^{\text {th }}$ Annual Global CEO Survey (2011) indicated that building global skills to bridge the gap of lack of globally competent managers was one of top concerns of MNCs. Being aware of the importance of cross-cultural leadership development to global business, majority of organizations actively seek a variety of approaches to improve global talent development (Kramer, 2005). However, Caligiuri and Tarique, (2012) pointed out that developing global leader was related as one of the least effective capabilities by over 700 chief human resource executives of IBM in 2010. Developing cross-cultural leadership is critical to both global leaders on international assignments and MNC success. It is important to understand what determines or shapes an effective cross-cultural leader before MNCs deploy methods or trainings to cultivate their global leaders.

Although the field of cross-cultural leadership development is in its infancy (Suutari, 2002), an increasing number of studies in recent years have examined issues related to developing cross-cultural/global leadership. Some investigated connections between culture and leadership to develop a systemic body of knowledge that solves the problems mentioned above (e.g., Dickson et al., 2003; Matviuk, 2007; House et al., 1997). Most focus on the relationship between culture and leadership styles (House et al., 2002; Dickson et al., 2003; Wong et al., 2007), with most authors applying Hofstede's cultural dimensions to test hypotheses (Matviuk, 2007; House et al., 1997), but little attention has been paid to discovering what determines whether a manager is an effective cross-cultural leader. Others proposed conceptual frameworks and models of cross-cultural/global leadership effectiveness (e.g., Caligiuri, 
2006; Mendenhall \& Bird, 2013). These proposed frameworks or models facilitate to identify core competencies an effective global leader must possess, but they lack empirical support. In a study that predicts global leadership effectiveness, Caligiuri and Tarique (2009) call for more empirical research.

Despite great efforts at examining cross-cultural leadership, studies regarding the experiences of global Asian leaders are limited (Dowling \& Welch, 2005), and the literature suggests that global leader management require more qualitative methods (Tarique \& Schuler, 2010) from non-Western, expatriate managers (Ayoko et al., 2004). Given this state of the literature, understanding the experiences of cross-cultural leadership during international assignments from Asian leaders is imperative. In line with a call from Tarique and Schuler (2010) for more qualitative methods to "facilitate grounded theory building" (p.129) in the field of global leader management, this study uses qualitative methods to explore critical determinants of the effectiveness of cross-cultural leadership from the perspectives of expatriate Asian managers. The primary questions to be examined in this study are: (a) what are core factors determining the effectiveness of cross-cultural leadership; and (b) how expatriate managers effectively execute leadership in cross-cultural context.

\section{Overview of Cross-cultural Leadership}

This study begins overview of cross-cultural leadership with a brief discussion of challenge of cross-cultural leadership. Next, research regarding effectiveness of cross-cultural leadership is followed. Finally, this study looks into need for effective cross-cultural leadership.

\subsection{Challenges of Cross-cultural Leadership}

A complex, changing, uncertain, and ambiguous global environment escalates challenges to global leaders. Research into cross-cultural leadership suggests that cross-cultural interactions (Zander et al., 2012), language barriers (Schweiger et al., 2003; Ko \& Yang, 2012), cultural disparities concerning work values, norms, and attitudes (Miroshnik, 2002; Dickson et al., 2003, Earley \& Ang, 2003; Thomas \& Inkson, 2004; Zander et al., 2012), and cross-cultural uncertainty (Stock \& Genisyürek, 2012; Sims \& Schraeder, 2004; Lee, 2007) are primary cultural challenges for leaders working in cross-cultural contexts. Other cross-cultural leadership challenges include identity-based conflicts (Chrobot-Mason et al., 2007), managing and motivating culturally diverse teams (Caligiuri \& Tarque, 2009), managing diverse cultures (Caligiuri, 2013), developing cross-cultural competencies (Caligiuri, 2013; Caligiuri \& Tarique, 2009), and adapting leadership styles (Steers et al., 2012).

Management of overseas subsidiaries is paramount to MNCs because the views, experiences, expertise, and performance of expatriate managers are essential to competiveness, expansion, and ultimate success of a company. Not surprisingly, MNCs place great importance on the quality of cross-cultural leadership, but not all international assignments are successful. The ratio of expatriate failure is discussed widely in the literature, with estimates ranging from $16 \%$ to $50 \%$ (Tung, 1981; Employee Benefit Plan Review, 2001), and financial costs from US\$200,000 to US\$1.2 million dollars (Swakkk, 1995; Solomon, 1996). Damaged reputations, losses of market shares and host national employees, losses of valued global leaders, and damaged relationships with host countries are major indirect costs the literature cites (Scullion \& Collings, 2006; Cassiday, 2005). The high ratio of expatriate failures, combined with both direct and indirect costs, causes serious concerns for MNCs, making selecting the right leader to manage and lead an overseas subsidiary increasingly essential.

\subsection{Effectiveness of Cross-cultural Leadership}

Caligiuri and Tarique (2009) argue that leaders who can manage in complex, changing, uncertain, and ambiguous global environments are essential to MNCs' future effectiveness. MNCs able to develop and deploy effective global leaders gain global competitive advantages in the future (Caligiuri, 2013). Exploring the topic, Deng and Gibson (2009) interview 41 expatriate managers working in Australian businesses that operate in China, finding that transformational leadership, emotional intelligence, and cultural intelligence are contributors to effective cross-cultural leadership. In a study that predicts effectiveness of global leadership with 256 global leaders from 17 countries working in U.K. diversified firms, Caligiuri and Tarique (2009) find that high-contact, cross-cultural leadership development experiences and leaders' personality characteristics are predictors. Based on attachment style, Manning (2003) suggests that relationship competencies and openness to new perspectives are crucial leadership characteristics related to cross-cultural leadership effectiveness. More recently, Caligiuri and Tarique (2012) survey 420 global leaders from three large MNCs, finding that dynamic, cross-cultural competencies (i.e., tolerance of ambiguity, cultural flexibility, and reduced ethnocentrism) relate to global leadership effectiveness. 
Some researchers propose conceptual frameworks and models to analyze and identify competencies and traits related to cross-cultural/global leadership effectiveness. Caligiuri (2006) proposes the KSAOs theory as a method to develop effective global leaders, suggesting, "Successful global leaders are likely to possess some common knowledge, skills, abilities, and other personality characteristics (KSAOs)" (p.220). According to Caligiuri (2006), knowledge includes culture-general knowledge, culture-specific knowledge, and intercultural business knowledge; skills and abilities encompass intercultural interaction skills, foreign language skills, and cognitive abilities; personality characteristics consist of extroversion, agreeableness, conscientiousness, emotional stability, and openness - the Big Five. In addition, Dunn et al. (2012) proposed a global leadership model — consisting of task, relationship, awareness, and purpose domains - to strengthen the foundation of leadership effectiveness. More recently, from a review of twenty years of research on global leadership competencies, Mendenhall and Bird (2013) present a conceptual model of global leadership competencies consisting of six categories: traits/attitudes, cognitive orientations, intercultural relationships, global business expertise, global organizing expertise, and visioning. These categories group into broader classes: technical and social competencies. Technical competencies include global business expertise, global organizing expertise, and visioning, and social competencies relate to traits and attitudes, cognitive orientations, and intercultural relationships. These conceptual frameworks and models proposed facilitate to identify core competencies or characteristics an effective cross-cultural leader must possess, but they are more normative than empirical. As noted by Beechler and Javidan (cited in Caligiuri \& Tarique, 2012), the available literature in the field of global leadership development is more normative than empirical, focusing on the discussions of issues and problems rather than dealing with theoretical or empirical challenges.

\subsection{Need for Effective Cross-cultural Leadership}

Successful international assignments benefit both MNCs and expatriate managers. MNCs employ expatriates to control global businesses (Dowling \& Welch, 2005), transfer know-how to subsidiaries (Evans et al., 2001), and deal with culturally diverse constituencies (Caligiuri \& Tarique, 2009). They export technologies and organizational culture to locals (Bennett et al., 2000), enhancing global integration and competiveness (Evans et al., 2001). Many researchers suggest international assignments present expatriates with opportunities to increase their own global perspectives, acquire further skills and knowledge of the world, and move up career ladders (Oddou \& Mendenhall, 1991; Tung, 2000, Bennett el al., 2000). These opportunities add greatly to the importance of effective global leaders and make cross-cultural leadership a top concern for MNCs.

In a study of global talent management, Tarique and Schuler (2010) argue, "There is considerable evidence that organizations worldwide face formidable talent challenge" (p.123). The 2005 Global Leadership Trend Survey Report indicates that the majority of organizations perceive a need to improve global talent development (Caligiuri \& Tarique, 2009). A study conducted by IBM (2010) indicates that developing future leaders rated by more than 700 chief resource management executives is the most important capability needed to achieve MNCs' global success in the future (Caligiuri \& Tarique, 2012). However, according to Gregersen, Morrison, and Black (1998), 85\% of Fortune 500 companies do not have an adequate number of global leaders, and $67 \%$ believe leaders require additional skills and knowledge. In their study of building an effective global business team, Govindaran and Gupta (2001) found that one-third of the 70 studied global teams were reported to fail to achieve intended goals. Poor cross-cultural leadership often leads to employee dissatisfaction and underperformance (Kraimer et al., 2001). Sculling and Collings (2006) suggested, "Effective global managers see the need to manage cultural differences and develop skills necessary to participate in the global environment" (p.67). Others argued that global managers should have reflexive capabilities to interact with culturally diverse teams (Ofori \& Toor, 2009). Researchers such as Alder (2006), Bond and Schermerhorn (1997), and Scullion and Collings (2006) suggested the need to prepare cross-cultural leaders for international assignments and global business matters, but lack of consensus regarding what makes a great global manager is a concern in the field (Forster, 2000; Scullion \& Collings, 2006). A study that examines determinants of cross-cultural leadership effectiveness would be revealing and add significantly to literature in the field.

\section{Methodology}

This study used a qualitative, in-depth interview approach to explore determinants of cross-cultural leadership effectiveness from the perspectives of Asian leaders. The method was chosen for two reasons. First, the purpose of this study required the researcher to understand the processes and actions of how leaders in an international context overcome challenges or stresses they encounter, including what methods and strategies they employ to achieve cross-cultural leadership effectiveness. Thus, detailed data were essential. Second, to achieve the goals of this study, 
the researcher not only needed to illicit views that are important factors to be an effective cross-cultural leader, but also to understand why the leaders believed the factors were important. The qualitative, in-depth interview approach has been recognized broadly as an effective tool that allows participants to describe experiences on a topic or situation as much as possible, enabling a researcher to conduct "guided conversation[s] with a goal of eliciting from the interviewee rich, detailed materials (Rossman \& Rallis, 1998, p.18). In addition, the method "may help provide crucial information about how and why individuals engage in intercultural contact and the kind of perceptions and evaluations they take from these moments." (Halualani, 2008, p.15). Qualitative, in-depth interviews were suited to capture the essences of participants' experiences of cross-cultural leadership to achieve the purpose of this study.

\subsection{Participants}

To portray and elicit the essences and experiences of cross-cultural leadership best, two selection criteria were used: (a) participants must have had at least two years of leadership experience during international assignments; and (b) participants must have resided in the host country for a minimum of two years. Letters recruiting participants were sent to CEOs of Taiwanese MNCs listed as top 100 service-based firms by Commonwealth, a standard business publication that Taiwanese readers regard as reliable. Five Taiwanese MNCs responded as willing to participate, so twelve expatriate managers who were middle and upper leaders were recruited. They were all Taiwanese males aged 35 to 66 with 2 to 30 years of experience of cross-cultural leadership during international assignments. Their assignments were in the United States, Germany, Australia, the Netherlands, Thailand, Malaysia, Indonesia, South Korea, Japan, and Singapore. Three participants relocated to more than two countries, and 5 had cross-cultural experiences during two international assignments. Diversity regarding the countries to which participants relocated and the affluence of their cross-cultural interactions provided opportunities for this study to explore knowledge, processes, essences, and experiences of cross-cultural leadership, and facilitated the researcher to achieve the goals of the study.

\subsection{Data Collection}

Data were collected through semi-structured interviews, self-evaluations of cross-cultural leadership, and demographics. An interview protocol was designed and used as a guideline to facilitate the interviews. To portray and understand the essences and knowledge concerning the effectiveness of cross-cultural leadership best, the interviews centered on three issues: (a) challenges of cross-cultural leadership; (b) processes of overcoming challenges of cross-cultural leadership; and (c) important competencies for effective cross-cultural leadership. All interviews were audio-taped with the permission of the participants, completed within two hours, and transcribed for analysis. Copies of the transcripts were sent to respective participants for correction and verification. Although the literature defines concepts and styles of leadership variously—some controversially (Suutri et al., 2002; Dickson et al., 2003) — the data provided common insights regarding managing people from disparate cultures.

Self-evaluations of cross-cultural leadership, with two open-ended questions concerning job-related leadership and cross-cultural, interpersonal communication leadership were distributed to participants following each interview. Job-related leadership refers to the effectiveness of expanding or maintaining overseas business, and cross-cultural, interpersonal communication leadership refers to the effectiveness of managing, motivating, and dealing with people from various cultural. Ten of 12 participants reported that they met the objectives of overseas business their organizations assigned to them, and the remainder reported that although they met their objectives, they needed to learn how to identify more business opportunities while overseas. In terms of cross-cultural, interpersonal communication leadership, ten participants reported that they managed, motivated, and dealt with people from disparate cultures effectively, and the remainder mentioned they were competent with those tasks, but needed to improve their leadership style regarding motivation. Demographic information included age, education, years of relocation, and countries of relocation, collected before the interviews.

\subsection{Data Analysis}

Open and axial coding (Strauss \& Corbin, 1990, 1998) were used to analyze data. Both types of coding can be summarized as categorization and connecting those categories (Ian, 1999). To facilitate coding, this study employed three analytic tools that Strauss and Corbin (1998) recommend: microanalysis, comparison, and coding paradigms. Data were coded through line-by-line analysis to identify concepts and their properties. Concepts pertaining to the same phenomenon were grouped using systematic comparisons. Hence, three categories (and subcategories and properties) emerged, including personality characteristics, leadership strategy, and core competency (Table 1). Axial coding was conducted by reassembling the data and making connections between categories to "form more precise and complete explanations about phenomena" (Strauss \& Corbin, 1998, p.124). Connections were guided by a coding paradigm, an organizational scheme used to sort and organize emerging connections between categories, 
involving components of conditions, contexts, actions/interactional strategies, and consequence (Strauss \& Corbin, 1998). Integration of developing and linking categories through open and axial coding led to a final set of categories and propositions, which revealed patterns of findings that explained phenomena related to cross-cultural leadership effectiveness.

Table 1. Categories and Subcategories $(\mathrm{N}=12)$

\begin{tabular}{llc}
\hline Main categories & Subcategories & $\begin{array}{c}\text { Number of } \\
\text { endorsements }\end{array}$ \\
\hline Personality Characteristics & Extroversion & 8 \\
& Integrity & 6 \\
& Open-mindedness & 10 \\
& Self-learning & 12 \\
& Sincerity & 9 \\
\hline Leadership Strategies & Building cohesion and harmony for & 10 \\
& successful teamwork & 12 \\
& Developing appropriate behavior & 12 \\
& Establishing interpersonal effective & 6 \\
& communication & 9 \\
& Fully empowering the subordinates & 12 \\
& Leading with the heart & \\
& Understanding and appreciating local & 12 \\
& culture & 12 \\
\hline Core Competencies & Communication skills & 12 \\
& Cultural intelligence & 10 \\
\hline
\end{tabular}

\section{Research Findings}

Analysis yielded three categories found to be determinants of cross-cultural leadership effectiveness: (a) personality characteristics, (b) leadership strategies, and (c) core competencies. Each category, including subcategories and properties, and links between them were depicted carefully by assembling perceptions, opinions, methods, and strategies of participants.

\subsection{Personality Characteristics}

All participants emphasized the importance of personality characteristics regarding cross-cultural leadership effectiveness. Integrity, self-learning, sincerity, open-mindedness, and extroversion stood as primary personal characteristics that enhanced execution of leadership strategies and facilitated development of competencies needed to deal with subordinates from disparate backgrounds and work toward expanding business overseas.

\subsubsection{Integrity}

Six managers indicated that integrity was a criterion for gaining the respect of local staff members and leading individuals from varying cultures. Participant 8 viewed integrity as "chapter one": "Management without integrity would have a lot of problems gaining respect from subordinates. An overseas subsidiary will not work well if the company assigns an expatriate without integrity." Participant 9 commented similarly, "Because banking is a service industry, as a CEO of an overseas subsidiary, I not only needed to lead the local staff, but also contact customers from all levels and all industries. This requires leadership integrity. Integrity is chapter one for effective leadership." In reference to his experiences, Participant 10 emphasized that for an expatriate manager, integrity is essential for success: "As an expatriate must have integrity and ethics. You cannot arbitrarily engage in improper business or defraud the organization. Success requires integrity and ethics." Participant 11 added, "If there is no integrity, there is no trust." Participant 9, CEO of an overseas subsidiary, shared similar views.

\subsubsection{Self-learning}

All participants reported the importance of self-learning to adjust to new living and working environments, and a need to acquire knowledge and skills to cope with local staff members' work habits and behaviors, which were often unpredictable. Participant 5 pointed out that MNCs should make self-learning a criterion for selection of expatriate 
managers.

You must learn by yourself. I think how much you want to learn depends on yourself. In fact, each department of the organization requires some specific knowledge. You must make an effort to understand the local culture, for different countries have different cultures, and you have to acquaint yourself with them if you wish to blend into their environment.

Participant 11 observed, "If an expatriate manager is more willing to learn and loves to absorbing knowledge, then he/she will be able to find out a way to adjust to the new work environment." Upon arriving in Germany, Participant 4 became irritated by the work attitude of his local subordinates, things such as inaction and dislike of closing time, the latter quite unlike work hours in Taiwan. To minimize the gap between him and his local subordinates and to increase team productivity, he decided to observe and learn the German culture. Participant 12, who relocated to Thailand, had a similar observation: "You must be well-prepared; you need to study all relevant regulations and laws as well as their cultural habits in order to be able to lead them."

\subsubsection{Sincerity}

Nine participants insisted on the significance of sincerity to achieving effective interactions and communications with subordinates. Participant 11 spoke directly about sincerity as a factor for earning the trust of local staff members: "You must be sincere; you must let them feel that you are standing with them, rather than over or beyond them. You must make them feel you are on their side and that you are fighting for them while dealing with the headquarters." Participants 2, 4, 5, 6, 7, 8, 11, and 12 mentioned the importance of sincerity when dealing with local staff members whose work habits were troublesome during the first few weeks of their overseas assignments; sincerity makes it easier to change local work attitudes. Participant 5 noted:

In fact, everyone should know what management in Southeast Asia entails. These people are more relaxed. We Taiwanese like to do things right away. Slowing down is not our style. Therefore, I was unhappy in the beginning because they were kind of slow. However, I learned the importance of earning their respect by speaking straight forwardly with them from the beginning.

\subsubsection{Open-mindedness}

The trait participants emphasized most was open-mindedness because it was helpful during all functions, from facilitating initial involvement in their work and living conditions to easing embracement of cultural disparities. Participants agreed that "you must be open-minded because you are dealing with people from different cultures" (Participant 2). "I feel I am a person who easily cooperates with others. Due to this personal characteristic, I will make an effort to blend into the local life when I enter a new environment which requires me to undergo some change" (Participant 6). "In fact, it is a process of interaction, not only they need to adjust to my thinking model, but I also need to adjust to theirs" (Participant 1). "Possessing the characteristic of open-mindedness is a critical asset that assists an expatriate's desire to get along with subordinates" (Participant 12).

\subsubsection{Extroversion}

Descriptions of extroversion emerged often (8 of 12 participants) regarding active engagement in the working environment to achieve success with handling a team of culturally diverse members. Participant 6 considered himself an extrovert, which led him to become immediately active and willing to understand local culture as a way to narrow the gap between himself and local subordinates. Participants 2 and 5 noted that extroversion facilitated their adjustments to both working and living environments, and helped them get along with local subordinates. Participant 8, who had twelve years of experience as an expatriate manager, said:

An extrovert fits more easily into the work of an overseas subsidiary. Specifically, an expatriate manager not only needs to handle his managing responsibilities, but also must deal with cross-cultural communication.

Answering a question concerning what makes for successful overseas management, Participant 11 stated, "You must be an extrovert in order to be willing to get along with people."

\subsection{Leadership Strategy}

Participants described in detail how they coped with cross-cultural interactions in a work context regarding leadership and management, and they listed several strategies: (a) leading with the heart; (b) empowering subordinates fully; (c) building cohesion and harmony for successful teamwork; and (d) establishing interpersonal communication stemming from understanding and appreciation of local cultures, and developing appropriate behaviors. 


\subsubsection{Leading with the Heart}

Nine participants stated that expatriate managers of a multicultural team must pay special attention to leading with the heart. Participant 12 emphasized, "You must lead them with your heart. A leader who manages his subordinates like a drill sergeant lacks sincerity." Participant 10 responded, "As a leader, you must count on your subordinates making some mistakes" because "making mistakes is one way to learn and grow." He added, "A leader must regard his followers as members of his family. If the subordinates realize this, they will know you will do anything for them, and even if they do not truly appreciate you, at least they will not cause you any problems." Participants 5 and 7 discussed a similar sentiment: "Trust. You must trust them. You must treat your subordinates well in order to establish a good relationship and increase team performance" (Participant 7). Participant 10 added:

As a leader, you must regard subordinates as your brothers and relatives. I do not promise you a job so that you are willing to follow me because you want to get a promotion and get rich. A leader leads subordinates to work together by offering them a chance for personal fulfillment and further learning about how to do good work.

Cultural disparities were salient as factors that challenged participants' leadership, leading some participants to sense it was important to gain subordinates' respect and support to enable them to work well. Participants cited a number of examples of leading with the heart. Participants 7 and 8 commented similarly about how "a leader knows the importance of setting the example for the rank-and-file because it will have a greater chance of gaining the respect of the subordinates" (Participant 8). Blending with subordinates was another way to lead with the heart:

I thought that it was necessary to blend into them in order to make them feel that you care about them. I always had dinner with them. They will respect you in a natural way and will sense your sincerity. (Participant 5)

You must be able to integrate information to adapt to the headquarters' demand. Then your personal characteristics should encourage you blend into with the local staff, for loyalty is important. Thus, you will earn their trust. (Participant 11)

\subsubsection{Empowering Subordinates Fully}

Six participants emphasized that full empowerment was an important leadership asset. Some reported it was a strategy for inspiring and motivating subordinates, though others saw it as an important factor for teamwork. Participant 10, who was responsible for an honor mission in Indonesia, was proud of his team's performance:

When I was in Hainan, I was informed that the Vice President was planning to visit Indonesia. It made me very proud to have such an opportunity... so I fully empowered my subordinates in Indonesia. Everything was done by teamwork. I believe it is important to make people trust you and themselves. We played our roles well there [in Indonesia] and brought into play the most effective tools of our organization. I felt wonderful.

Participant 11 stated pointedly, "Full empowerment is very important to teamwork in terms of morale and motivation to bring the best out of your subordinates." Participant 7 characterized full empowerment from another perspective:

An overseas subsidiary is very different from the headquarters because you face different issues which require that you empower your local subordinate to carry out certain tasks. In particular, it is not always possible for you to communicate with the local nationals in English, since they do not speak English. It is, then, up to one of your subordinates to deal with them.

\subsubsection{Building Cohesion and Harmony for Successful Teamwork}

Ten participants expressed that building cohesion and harmony is crucial for leaders when leading cross-cultural teams because it is relevant to the successes of their assignments. As a manager of a foreign subsidiary for many years, Participant 8 acknowledged, "The success of an expatriate manager depends on the help and support of many people around him/her," and he recommended, "Everybody unite as one," local co-workers and managers alike. Participant 10 similarly illustrated his leadership strategy from the perspective of teamwork and cohesion. He believed effective teamwork associated with good performance during each role because it encouraged an effective organization. He also attributed effective performance to teamwork. Participant 10 considered cohesion critical to effective leadership and teamwork:

You must make the subordinates feel they respect you in earnest admiration, without hesitation, and are willing to do their best. If so, you are for them like their President, admired by people who want to follow your example. This leads to cohesion, which is a centripetal force. Therefore, this is what an administrator must do.

Both Participants 11 and 12 accentuated the significance of cohesion. Participant 11 said, "The most important thing a leader should avoid while operating and managing a company is whatever leads to the formation of factions; a leader must try his/her best to create a climate that is not conducive to the formation of small separate groups." 
Participant 11 used a circle metaphor to highlight how important cohesion is for a multicultural team: "It is very important to think of ways to bind together all team members in order to form a very strong force to serve customers and to engage in business competition." Participant 12 pointed out the importance of playing the role of bridge-maker between headquarters and an overseas subsidiary, and while managing local and non-local subordinates. He saw himself as a communicator because headquarters had too many windows, and "you must make some adjustments. Harmony is very important within an organization."

\subsubsection{Establishing Interpersonal Communication}

To overcome communication barriers created by cultural disparities between expatriate managers and local subordinates, all participants established communication through understanding and appreciation of local cultures, and by developing appropriate behaviors. Clarity, accuracy, respect, and sincerity were components of appropriate behaviors, and they learned how to understand and appreciate local cultures and adopt ways to deal with cross-cultural interactions.

Participant 11 observed, "In fact, it is necessary for a multicultural team to communicate well because without proper communication, the barriers will multiply." He believed "having adequate communication can help you remove the barriers," adding, "Conveying clear orders" to subordinates who are nationals of the host country is important because of cultural differences. "You must consider whether he/she can understand the information being conveyed." Participant 10 said, "All human beings are the same, but can be difficult to deal with, so the difference in communication strategy between the host country subordinates and the headquarters is mostly in tone." He stressed the importance of conveying information and orders to other people clearly.

Participant 6 stressed, "Misunderstanding in communicating with colleagues is the major factor leading to conflicts." It is important to provide "clear explanations about why things are to be done" because it is the best way to improve the effectiveness of communication and reduce conflicts resulting from misunderstanding (Participants 10,11, \& 12). After noting, "There are two main different cultures - Oriental and Western-within the local unit organization" and pointing out, "Americans are more straightforward and explicit," Participant 3 reported that he adopted a straightforward strategy and attitude to communicate with local staff members while transferring knowledge to them. Respect (Participants 8, 10,11, \& 12) and sincerity (Participants 1, 2, 3, 5, 8, 10,11, \& 12) contributed to effective communication, combined with knowledge and understanding of local culture.

\subsection{Core Competencies}

Cultural intelligence, communication skills, professional knowledge and skills, and English-speaking ability were the most important skills an expatriate manager should possess and integrate to lead culturally diverse subordinates.

\subsubsection{Cultural Intelligence}

All participants recognized cultural disparities and understood the need to acquire knowledge of local cultures to develop a repertoire of appropriate behaviors during cross-cultural interactions. Differences in work behaviors and attitudes between local staff members and headquarters prompted Participant 2 to notice a gap between the two. After realizing that cultural disparities played a role in the work habits of both local and home-country staff members, he concluded that it would be inappropriate to impose headquarters' culture on a foreign subsidiary. Similarly, Participant 5 was exasperated by the behaviors of local staff members toward work during initial stages of his international assignment because he saw them as too relaxed and focused on face-saving. However, he gradually adjusted to his new work environment after understanding local culture by socializing with subordinates after-hours. His willingness to learn and "accept cultural differences" made him reshape his management attitudes toward local subordinates. "I slowed down my pace, although not as slow as theirs. But I made some adjustments, something like from 100 to 70 points. Still, it was not possible to get down to 20 or 30." Thus, he demonstrated greater understanding of local culture and adopted a more open-minded approach toward locals do his job more effectively. "You must blend in with them; you must accept. Otherwise, employee's resignations will follow."

Participant 10 mentioned that his ability to adapt and his openness to accept and understand local culture were critical to integrating into a new culture, and to installing his style of management in the local subsidiary:

You had to adjust your mindset when you were transferred from a very hurried environment to a foreign country. Everything was different; you had to adjust your ways, including your pace, to ease yourself into the local environment. In addition, you had to consult with your predecessor about local taboos and customs.

Participant 12 attributed success regarding approval of a subsidiary company in Thailand to a combination of integrating understanding of organizational, local, and host-nation cultures. He acknowledged being: 
not very knowledgeable in these issues, [yet] a willingness to blend into the group of local subordinates was very important because they will help you and understand you better. You must pay more attention to understanding the local culture and the way of thinking of the host nation in countries where the financial system and regulations are not sound enough.

\subsubsection{Communication Skills}

All participants recognized that competency with communication facilitates cross-cultural interactions with local subordinates, but they expressed opinions on the issue from various viewpoints. Participant 1 was direct in saying "communications competency" is the most important asset for the success of an expatriate manager. He regarded it a weapon that greatly enhances one's capabilities when matched with other abilities. Participant 2 noted that a skilled communicator can more easily allay the doubts of local staff members regarding his/her managing qualifications, doubts that derive from the fact that their experiences are more extensive than his/hers. Participant 1 said, "Communication skills are very important because they can make up for the lack of language fluency and can enable you to play the role of the bridge-maker between the headquarters and the locals." Participant 12 saw positive communication as critical to an expatriate's efforts to expand business and establish good relations with everyone. "Communicating well with the subordinates is very important for the success of an international assignment," noted Participant 9.

\subsubsection{Professional Knowledge and Skills}

Regardless of the nature of international assignments or the peculiarities of local cultures, 10 participants indicated that professional knowledge and skills are requirements for leadership. Participant 10 stressed that professional knowledge and skills are crucial to management of teamwork, especially in a multicultural team: "You must be a professional in your field. Your professional knowledge enables you to go abroad to charge and shatter the enemy's position and to lead your team." Participant 8 said, "As a general manager, having a high level of professional knowledge and skills is important because it will help you make accurate judgments and will increase the trust of your local subordinates." Participant 7 took a slightly different perspective: "You must possess professional knowledge and skills in order to be able to lead them, replace them, and provide them with directions." Some participants indicated that it is crucial to possess professional knowledge and skills to earn prestige and authority, along with the respect of local staff members. Participant 11 stated, "Your prestige and authority are firmly established if you are able to respond accurately to the questions of the local staff, and that you will be able to play your role well." Participant 1 emphasized the importance of professional knowledge when leading local staff members because these people regarded him as an airborne trooper from headquarters and doubted his work experience.

\subsubsection{Language Ability}

All participants highlighted that mastering English was a prerequisite for the success of the managers. "Basic prerequisite skill," "very important prerequisite," and "prerequisite" were terms used to describe and emphasize the need for English fluency in cross-cultural interactions and leading culturally diverse teams.

Participants 1 and 4, who both relocated to Germany, emphasized a need for English fluency in their adjustments to the culture, and in facilitating communication with local staff members. Participant 1 recounted, "I feel that, for an expatriate, the ability to speak English is a critical component in facilitating communication and interaction with the local staff." Participant 2 added, "Language ability is a prerequisite of cross-cultural communication. Because of my English-speaking ability, I encountered no barrier that prevented me from communicating with others." Participant 12 emphasized, "English ability is very important and critical to business, leadership, and communication because an expatriate manager needs to expand the business, lead teamwork, and communicate with others." Participant 10 stressed the importance of English fluency from another perspective: "The language requirement [English] is not up for discussion; it is rather a prerequisite, the same as fluency in Chinese, because you are working in a service industry, particularly a global service industry." Participant 7 commented, "To be an expatriate manager, your English has to be good because it is an essential tool. What can you contribute to the organization if you are unable to articulate your own thoughts?"

\section{Theoretical Propositions}

Integration of findings generated four propositions that depict the most critical determinants to shaping global leaders and making cross-cultural leadership effective.

1) A global leader's effectiveness is a function of the integration of personality, leadership strategies, and 
competencies.

2) Personality characteristics enhance execution of leadership strategies and facilitate development of competencies of cross-cultural leadership needed to deal with subordinates from disparate cultures. Integrity, sincerity, self-learning, open-mindedness, and extroversion are traits required for success.

3) Execution of leadership strategies determines a global leader's effectiveness, which include leading with heart, empowering subordinates fully, building cohesion and harmony for teamwork, and establishing interpersonal communication from an understanding and appreciation of local cultures and developing appropriate behaviors.

4) Cross-cultural leadership effectiveness calls for cultural intelligence, communication skills, professional knowledge and skills, and language ability.

\section{Conclusion and Discussion}

This study explores facets that determine the effectiveness of cross-cultural leadership from a non-Western perspective. Based on the nature of qualitative research, a small sample, and unique groups of participants, no intention was made to generalize to a population, though results were grounded in data. Results suggest that personality characteristics, leadership strategies, and competencies are three determinates that prepare and influence expatriate leaders regarding cross-cultural leadership effectiveness. The expatriate leaders examined in this study possessed salient traits that either enhanced their execution of leadership strategies or facilitated development of competencies for effective cross-cultural leadership. They were aware of the cultural disparities that presented challenges to leadership, and to deal with these challenges, they were proactive by learning about local cultures, deploying a number of leadership strategies, and developing and integrating competencies needed for effectiveness when leading a culturally diverse team.

This study suggests that effective leadership in a cross-cultural work environment requires integrity, self-learning, sincerity, open-mindedness, and extroversion. This finding accords with extant studies that suggest personality traits facilitate effective acquisition of leadership skills (Buss, 1991), foster effectiveness of global leadership (Caligiuri \& Tarique, 2009, 2012), and enhance completion of an overseas assignment (Caligiuri, 2000; Earley \& Ang, 2003). Earley and Ang (2003) argue that the big-five personality characteristics-extroversion, emotional stability, openness, agreeableness, and conscientiousness - associate with the effectiveness and success of expatriate managers' performance. In comparison to Earley and Ang's (2003) arguments, it is important to note that integrity, sincerity, and self-learning are personality characteristics identified rarely in cross-cultural leadership literature, and open-mindedness and extroversion are frequently found to relate to global leadership effectiveness (Caligiuri \& Tarique, 2009; Earley \& Ang, 2003). This difference might be explained from the perspective of culture and cultural values. Since Taiwanese people are educated to be humble and less self-absorbed - traits that enhance getting along with people, escalating their willingness to observe and learn - it is understandable why the expatriate managers displayed sincerity and self-learning personal traits during cross-cultural leadership. This accords with Daoist leadership, which suggests "modesty or humbleness, willingness to help and benefit others and the ability to maintain a low profile are qualities essential to a good leader" (Lee et al., 2014, p.268). According to Laozi, modest and humble people not only demonstrate harmony with others, but are also effective leaders (Lee et al., 2014).

An important finding was that personality characteristics facilitate development of competencies needed for effective cross-cultural leadership. This supports research that suggests dispositional disparities influence developmental outcomes such as effectiveness in cross-cultural leadership (Caligiuri \& Tarique, 2009). It also highlights the importance of personality characteristics in accelerating acquisition of cross-cultural competencies, predicting cross-cultural leadership effectiveness, and enabling leaders to make faster developmental gains through international assignments (Caligiuri, 2013). The finding is also in line with Mendenhall and Bird's (2013) argument that "some competencies provide a platform on which other competencies are predicted" (p.172).

Results of this study suggest that leadership strategies influence the effectiveness of cross-cultural leadership. Leading with heart and building cohesion and harmony to encourage teamwork, discussed rarely in cross-cultural leadership literature, were important leadership strategies participants deployed to overcome the challenges of cultural disparities, establish relationships with local subordinates, and increase the effectiveness of both leadership and performance. Given the collective orientation of the culture of these Taiwanese expatriate managers, it is unsurprising that all participants emphasized the importance of harmony, cohesion, and teamwork. Adler (1997) remarked, "Members of a collectivist culture place importance on fitting-in harmoniously and saving face" (p. 48), suggesting leaders' cultural orientations influence leadership style. Similarly, Triandis (1993) suggests that in 
collective cultures, successful leaders should be supportive and paternalistic. This study suggests that full empowerment is critical to cross-cultural teamwork because it motivates and inspires subordinates. Furthermore, this study demonstrates that cross-cultural communication is an essential strategy for effective leadership during international assignments.

Results demonstrate that cultural intelligence, communication skills, professional knowledge and skills, and language ability are core competencies expatriate managers possessed, required for cross-cultural leadership. All participants acquired the competency of cultural intelligence through self-learning, diving into cross-cultural interactions, and developing keen cultural awareness, a finding consistent with Thomas and Inkson's (2004) argument that cultural intelligence is a social learning process. Brislin, Worthley, and MacNab (2006) note that cultural intelligence can be developed, facilitating leaders' understanding of people from varying cultures. The finding that cultural intelligence is a core competency that relates to cross-cultural leadership effectiveness supports extant conceptual and empirical research that suggests cultural intelligence is a contributor to effective cross-cultural leadership (Thomas \& Inkson, 2004; Caligiuri, 2006; Deng \& Gibson, 2009; Dunn et al., 2012). Results also show that communication skills enhance leadership capabilities, supplement inadequate language skills, garner trust from and establish relationships with local subordinates, and play the role of bridge-maker between headquarters and locals. Most participants stressed professional knowledge and skills highly, relating to the effectiveness of leadership since they believed it helps expatriate managers make accurate business judgments, gain trust, and establish prestige and authority. Unsurprisingly, results advance the notion that English is the dominant language of communication in an era of globalization.

Grisham (2006) questions whether there exist cross-cultural leadership dimensions that are effective internationally, regardless of culture. Others argue that determinants of effective leadership vary across cultures (Hale Öner, 2012). Results of this study suggest similarities and disparities between Western and Eastern leaders regarding cross-cultural leadership effectiveness. Although no Western leadership and management theories were adopted or combined into a framework in this study, results of three determinants of cross-cultural leadership effectiveness produced convergent results that accord with Caligiuri and Tarique's $(2009,2012)$ research, Caligiuri's (2006) KSAOs theory, and Mendenhall and Bird's (2013) global leadership competencies model. Results of this study regarding competencies critical to cross-cultural leadership effectiveness advance and are consistent with empirical research on the topic. These results suggest that despite cultural disparities, some leadership attributes and styles are universal (Ofori \& Toor, 2009). On the other hand, despite personality characteristics found to be international dimensions of effective leadership determinants, their attributes were culturally different. Results regarding leadership strategies suggest full empowerment and interpersonal communication are important to cross-cultural leadership effectiveness that is common in Western literature. Leading with heart and building cohesion and harmony for teamwork are unique cultural values in Taiwan, a collective society. Communication skills, professional knowledge and skills, and integrity are competencies or traits relevant to gaining trust and establishing prestige and authority, terms highlighted repeatedly by leaders addressing effectiveness in a cross-cultural context.

\subsection{Limitations}

The sample was limited to a group of people from one cultural background, focusing primarily on their interactions with subordinates. Using self-reports to complement data sources might have led to apprehension to report all beliefs or experiences. This study was bounded by industry, corporation style, and national cultural orientation.

\subsection{Implications}

This study offers four propositions regarding determinants of cross-cultural leadership effectiveness during international assignments by examining how expatriate managers assigned overseas lead culturally diverse workforces. Findings provide insightful information, facts, and facets related to the practice of cross-cultural leadership from the perspectives of Asian expatriate managers. Results also provide empirical evidence that contributes to the theory of cross-cultural leadership, expatriate management, and global leadership development, and evidence for expatriate managers, trainers, and MNCs. Results might help expatriate managers who are in charge of multicultural teams and struggling to improve or reinforce leadership effectiveness and develop leadership strategies and competencies needed to enhance cross-cultural leadership. Acquiring competency in English and improving professional knowledge and skills before relocation are prerequisites for expatriate managers. Results demonstrate that MNCs should consider personality traits during selection of expatriate managers. Results also emphasize a need for MNCs to incorporate communication competency, cultural intelligence, and English training into their cross-cultural training. Findings also provide empirical propositions for cross-cultural leadership, encouraging researchers to test them using quantitative methods. Varying countries or regions should be included in 
future research. The influence of organizational culture on the leadership of expatriate managers needs to be explored, including local social contexts. Although this study contributes to theories of cross-cultural leadership during international assignments by adding a non-Western perspective, understanding the effectiveness of cross-cultural leadership from a non-Western perspective is imperative and requires more research.

\section{References}

Adler, N. J. (1997). International dimensions of organizational behavior (3rd ed.). Cincinnati, OH: South-Western College Publishing.

Adler, N. J. (2006). The arts \& leadership: Now that we can do anything, what will we do?. Academy of Management Learning \& Education, 5(4), 486-499. http://dx.doi.org/10.5465/AMLE.2006.23473209

Ayoko, O., Hartel. C., Fisher, G., \& Fujimoto, Y. (2004). Communication competence in cross-cultural business interaction. In D. Tourish \& O. Hargie (Eds.), Key issues in organizational communication (pp. 157-171). New York, NY: Routledge,

Bennett, R., Aston, A., \& Colquhoun, T. (2000). Cross-cultural training: a critical step in ensuring the success of international assignments. Human Resources Management, 39(2/3), 239-250. http://dx.doi.org/10.1002/1099-050X(200022/23)39:2/3<239::AID-HRM12>3.0.CO;2-J

Bond, M. H, \& Schermerhorn, J. R. (1997). Cross-cultural leadership dynamics in collectivism and high power distance settings. Leadership \& Organizational Development Journal, 18(4), 187-193. http://dx.doi.org/10.1108/01437739710182287

Brislin, R., Worthley, R., \& MacNab, B. (2006). Cultural intelligence: understanding behaviors that serve people's goals. Group and Organization Management, 31(1), 40-55. http://dx.doi.org/10.1177/1059601105275262

Buss, D. M. (1991). Evolutionary personality psychology. In M. R. Rosenzweig \& L. W. Porter (Eds.), Annual review of psychology (pp. 459-492). Palo Alto, CA: Annual Reviews Inc. http://dx.doi.org/10.1146/annurev.ps.42.020191.002331

Caligiur, P. (2013). Developing culturally agile global business. Organizational Dynamics, 42, 175-282. http://dx.doi.org/10.1016/j.orgdyn.2013.06.002

Caligiuri, P., \& Tarique, I. (2009). Predicting effectiveness in global leadership activities. World Business, 44, 336-346. http://dx.doi.org/10.1016/j.jwb.2008.11.005

Caligiuri, P., \& Tarique, I. (2012). Dynamic cross-cultural competencies and global leadership effectiveness. Journal of World Business, 47, 612-622. http://dx.doi.org/10.1016/j.jwb.2012.01.014

Caligiuri. P. (2000). The big five personality characteristics as predictors of expatriates desire to terminate the assignment and supervisor-rated performance. Personnel Psychology, 53, 67-88. http://dx.doi.org/10.1111/j.1744-6570.2000.tb00194.x

Caligiuri. P. (2006). Developing global leaders. Human Resource Management Review, 16, 219-228. http://dx.doi.org/10.1016/j.hrmr.2006.03.009

Cassiday, P. A. (2005). Expatriate leadership: an organizational resource for collaboration. International Journal of Intercultural Relations, 29, 391-408. http://dx.doi.org/10.1016/j.ijintrel.2005.05.012

Chrobot-Mason, D., Ruderman, M. N., Weber. T. J., Ohlott, P. J., \& Dalton, M.A. (2007). Illuminating a cross-cultural leadership challenge: when identity group collide. International Journal of Human Resource Management, 18(11), 2011-2036. http://dx.doi.org/10.1080/09585190701639778

Deng, L., \& Gibson, P. (2009). Mapping and modeling the capacities that underlie effective cross-cultural leadership. Cross Cultural Management: An International Journal, 16(4), 347-366. http://dx.doi.org/10.1108/13527600911000339

Dickson, M. W., Hartog, D. N., \& Mitchelson, J. K. (2003). Research on leadership in a cross-cultural context: making progress, and raising new questions. Leadership Quarterly, 14, 729-768. http://dx.doi.org/10.1016/j.leaqua.2003.09.002

Dowling, P. J., \& Welch, D. E. (2005). International human resource management: Managing people in an international context (4th ed.). Mason, $\mathrm{OH}$ : South-Western.

Dunn, T. E., Lafferty, C. L., \& Alford, K. L. (2012). Global leadership: a new framework for a changing world. SAM 
Advanced Management Journal, Spring, 4-14.

Earley, P. C., \& Ang, S. (2003). Cultural intelligence: individual interaction across cultures. Stanford, CA: Stanford University Press.

Employee Benefit Plan Review. (2001). Survey of expatriates shows differing employer-employee perceptions. 55(12), 40-41.

Evans, P., Pucik, V., \& Barsoux, J. L. (2001). The global challenge: frameworks for international human resources management. Boston Burr Ridge, IL: McGraw-Hill Irwin.

Forster, N. (1997). The persistent myth of high expatriate failure rates: a reappraisal. The International Journal of Human Resources Management, 8(4), 414-433. http://dx.doi.org/10.1080/095851997341531

Forster, N. (2000). Expatriates and the impact of cross-cultural training. Human Resources Management Journal, 10(3), 63-78. http://dx.doi.org/10.1111/j.1748-8583.2000.tb00027.x

Govindaran, V., \& Gupta, A. (2001). Building an effective global business team. Sloan Management Review, 42(4), 63-71.

Gregersen, H. B., Morrison, A. J., \& Black, J. S. (1998). Developing leaders for the global frontier. Sloan Management Review, 40(1), 21-33.

Grisham, T. (2006). Metaphor, poetry, storytelling and cross-cultural leadership. Management Decision, 44(4), 486-503. http://dx.doi.org/10.1108/00251740610663027

Hale Öner, Z. (2012). Servant leadership and paternalistic leadership styles in the Turkish business context: a comparative empirical study. Leadership \& Organization Development Journal, 33(3), 300-316. http://dx.doi.org/10.1108/01437731211216489

Halualani, R. T. (2008). How do multicultural university students define and make sense of intercultural contact?: A qualitative study. International Journal of Intercultural Relations, 32, 1-16. http://dx.doi.org/10.1016/j.ijintrel.2007.10.006

House, R., Javidan, M., Hanges, P., \& Dorfman, P. (2002). Understanding cultures and implicit leadership theories across the globe: an introduction to project GLOBE. Journal of World Business, 37, 3-10. http://dx.doi.org/10.1016/S1090-9516(01)00069-4

Ian, D. (1999). Grounding grounded theory: guidelines for qualitative inquiry. San Diego, CA: Academic Press.

Johnson, J. P., Lenartowicz, T., \& Apud, S. (2006). Cross-cultural competence in international business: toward a definition and a model. Journal of International Business Studies, 37, 525-543. http://dx.doi.org/10.1057/palgrave.jibs.8400205

Ko, H. C., \& Yang, M. L. (2011). The effects of cross-cultural training on expatriate management. Intercultural Communication Studies, $X X(1), 158-174$.

Kouzes, J. M., \& Posner, B. Z. (2008). The Leadership Challenge (4th ed.). New York: Wiley.

Kraimer, M. L., Wayne, S. J., \& Jaworski, R. A. (2001). Sources of support and expatriate performance: the mediating role of expatriate adjustment. Personnel Psychology, 54, 71-99. http://dx.doi.org/10.1111/j.1744-6570.2001.tb00086.x

Kramer, R. (2005). Developing global leaders. New York: The Conference Board.

Lee, H. W. (2007). Factors that influence expatriate failure: an interview study. International Journal of Management, 24, 403-413.

Lee, Y. T., Haught, H., Chen, K., \& Chen, S. (2014). Examining Daoist big-five Leadership in cross-cultural and gender perspectives. Asian American Journal of Psychology, 4(4), 267-276. http://dx.doi.org/10.1037/a0035180

Livemore, D. (2010). Leading with cultural intelligence: the new secret to success. New York, NY: American Management Association.

Manning, T. T. (2003). Leadership across cultures: attachment style influences. Journal of Leadership and Organizational Studies, 9(3), 20-30. http://dx.doi.org/10.1177/107179190300900304

Matviuk, S. (2007). Cross-cultural leadership behavior expectation: a comparison between United States managers and Mexican managers. Journal of American Academy of Business, 11(1), 253-260. 
Mendenhall, M. E., \& Bird, A. (2013). In search of global leadership. Organizational Dynamics, 42, 167-174. http://dx.doi.org/10.1016/j.orgdyn.2013.06.001

Miroshnik, V. (2002). Culture and international management: a review. The Journal of Management Development, 21(7), 521-544. http://dx.doi.org/10.1108/02621710210434647

Oddou, G., \& Mendenhall, M. E. (1991). Succession planning for the 21st century: how well are we grooming our future business leaders?. Business Horizons, 34, 26-34. http://dx.doi.org/10.1016/0007-6813(91)90078-A

Ofori, G., \& Toor, S. U. R. (2009). Research on cross-cultural leadership and management in construction: a review and directions for future research. Construction Management and Economics, 27, 119-133. http://dx.doi.org/10.1080/01446190802616937

PriceWaterhouseCoopers's Annual Global CEO Survey (2011). Growth reimagined: prospect in emerging market drive CEO confidence. PriceWaterhouseCoopers.

Rossman, G. B., \& Rallis, S. F. (1998). Learning in the field: an introduction to qualitative research. Thousand Oaks, CA: Sage Publications,.

Schweiger, D. M., Atamer, T., \& Calori, R. (2003). Transnational project teams and networks: making the multinational organization more effective. Journal of World Business, 38, 127-140. http://dx.doi.org/10.1016/S1090-9516(03)00006-3

Scullion, H., \& Collings, D. G. (2006). International recruitment and selection. In H. Scullion \& D. G. Collings (Eds.), Global staffing (pp. 68-86). New York, NY: Routledge,

Shaw, S. M., \& Meier, J. (1993). Second generation MNCs in China. The McKinsey Quarterly , 4, 3-16.

Sims, R. H., \& Schraeder, M. (2004). An examination of salient factors affecting expatriate culture shock. Journal of Business and Management, 10, 73-87.

Solomon, C. (1996). Danger below! Spot failure global assignments. Personnel Journal, 75(11), 78-85.

Steers, R. M., Sanchez-Runde, C., \& Nardon, L. (2012). Leadership in a global context: New directions in research and theory development. Journal of World Business, 47, 479-482. http://dx.doi.org/10.1016/j.jwb.2012.01.001

Stock, R. M., \& Genisyürek, N. (2012). A taxonomy of expatriate leaders' cross-cultural uncertainty: insight into the leader-employee dyad. The International Journal of Human Resource Management, 23(15), 3258-3286. http://dx.doi.org/10.1080/09585192.2011.637064

Strauss, A., \& Corbin, A. (1990). Basics of qualitative research: techniques and procedures for developing grounded theory. Thousand Oaks, CA: Sage Publications.

Strauss, A., \& Corbin, A. (1998). Basics of qualitative research: techniques and procedures for developing grounded theory (2nd ed.). Thousand Oaks, CA: Sage Publications.

Suutari, V. (2002). Global leader development: An emerging research agenda. Career Development, 7, 218-233. http://dx.doi.org/10.1108/13620430210431307

Suutari, V., Raharjo, K., \& Riikkila, T. (2002). The challenge of cross-cultural leadership interaction: Finnish expatriates in Indonesia. Career Development International, 7(6/7), 415-427. http://dx.doi.org/10.1108/13620430210449948

Swaak, R. (1995). Expatriate failure: too many, too much cost, too little planning. Compensation and Benefits Review, 27(6), 47-55. http://dx.doi.org/10.1177/088636879502700609

Tarique, I., \& Schuler, R. S. (2010). Global talent management: literature review, integrative framework, and suggestions for future research. Journal of World Business, 45, 122-133. http://dx.doi.org/10.1016/j.jwb.2009.09.019

Thomas, D. C., \& Inkson, K. (2004). People skills for global business: cultural intelligence. San Francisco, CA: Berrett-Koehler Publishers.

Triandis, H. C. (1993). Collectivism and Individualisms as cultural syndromes. Cross-Cultural Research, 27(3/4), 155-180. http://dx.doi.org/10.1177/106939719302700301

Tung, R. L. (1981). Selection and training of personnel for overseas assignments. Columbia Journal of World Business, 16 (1), 68-78.

Tung, R. L. (2000). American expatriate abroad: From neophytes to cosmopolitans. In G. Oddou \& M. Mendenhall 
(Eds.), Reading and cases in international human resources management (3rd ed., pp. 487-507). Cincinnati, OH: South-Western College Publishing.

Wong, J., Wong, P. N., \& Li, H. (2007). An investigation of leadership styles and relationship cultures of Chinese and expatiate managers in multinational construction companies in Hong Kong. Construction Management and Economics, 25(1), 95-106. http://dx.doi.org/10.1080/01446190600632573

Zander, Z., Mockaitis, A. I., \& Butler, C. L. (2012). Leading global teams. Journal of World Business, 47, $592-603$. http://dx.doi.org/10.1016/j.jwb.2012.01.012 